\title{
Molecular phylogenetics and mitogenomics of three avian dicrocoeliids (Digenea: Dicrocoeliidae) and comparison with mammalian dicrocoeliids
}

\author{
Suleman ${ }^{1,2}$, Mian Sayed Khan², Vasyl V. Tkach ${ }^{3 *}$, Nehaz Muhammad ${ }^{1}$, Dong Zhang ${ }^{4}$, Xing-Quan Zhu ${ }^{1,5^{*}}$
} and Jun $\mathrm{Ma}^{1 *+}$

\begin{abstract}
Background: The Dicrocoeliidae are digenetic trematodes mostly parasitic in the bile ducts and gall bladder of various avian and mammalian hosts. Until recently their systematics was based on morphological data only. Due to the high morphological uniformity across multiple dicrocoeliid taxa and insufficient knowledge of relative systematic value of traditionally used morphological characters, their taxonomy has always been unstable. Therefore, DNA sequence data provide a critical independent source of characters for phylogenetic inference and improvement of the system.

Methods: We examined the phylogenetic affinities of three avian dicrocoeliids representing the genera Brachylecithum, Brachydistomum and Lyperosomum, using partial sequences of the nuclear large ribosomal subunit (28S) RNA gene. We also sequenced the complete or nearly complete mitogenomes of these three isolates and conducted a comparative mitogenomic analysis with the previously available mitogenomes from three mammalian dicrocoeliids (from 2 different genera) and examined the phylogenetic position of the family Dicrocoeliidae within the order Plagiorchiida based on concatenated nucleotide sequences of all mitochondrial genes (except trnG and trnE).

Results: Combined nucleotide diversity, Kimura-2-parameter distance, non-synonymous/synonymous substitutions ratio and average sequence identity analyses consistently demonstrated that cox 1 , cytb, nad 1 and two rRNAs were the most conserved and atp6, nad5, nad3 and nad2 were the most variable genes across dicrocoeliid mitogenomes. Phylogenetic analyses based on mtDNA sequences did not support the close relatedness of the Paragonimidae and Dicrocoeliidae and suggested non-monophyly of the Gorgoderoidea as currently recognized.

Conclusions: Our results show that fast-evolving mitochondrial genes atp6, nad5 and nad3 would be better markers than slow-evolving genes cox 1 and nad 1 for species discrimination and population level studies in the Dicrocoeliidae.
\end{abstract}

\footnotetext{
*Correspondence: vasyl.tkach@und.edu; xingquanzhu1@hotmail.com; majun@caas.cn

${ }^{\dagger}$ Dr. Jun Ma is the principal corresponding author

1 State Key Laboratory of Veterinary Etiological Biology, Key Laboratory of Veterinary Parasitology of Gansu Province, Lanzhou Veterinary Research Institute, Chinese Academy of Agricultural Sciences, Lanzhou 730046, Gansu, People's Republic of China

${ }^{3}$ Department of Biology, University of North Dakota, Grand Forks, ND 58202-9019, USA

Full list of author information is available at the end of the article
}

c) The Author(s) 2020. This article is licensed under a Creative Commons Attribution 4.0 International License, which permits use, sharing, adaptation, distribution and reproduction in any medium or format, as long as you give appropriate credit to the original author(s) and the source, provide a link to the Creative Commons licence, and indicate if changes were made. The images or other third party material in this article are included in the article's Creative Commons licence, unless indicated otherwise in a credit line to the material. If material is not included in the article's Creative Commons licence and your intended use is not permitted by statutory regulation or exceeds the permitted use, you will need to obtain permission directly from the copyright holder. To view a copy of this licence, visit http://creativeco mmons.org/licenses/by/4.0/. The Creative Commons Public Domain Dedication waiver (http://creativecommons.org/publicdomain/ zero/1.0/) applies to the data made available in this article, unless otherwise stated in a credit line to the data. 
Furthermore, the Dicrocoeliidae being outside of the clade containing other xiphidiatan trematodes suggests a need for the re-evaluation of the taxonomic content of the Xiphidiata.

Keywords: Dicrocoeliidae, Nucleotide diversity, Mitochondrial genomes, Molecular phylogeny

\section{Background}

The Dicrocoeliidae Looss, 1899 is a highly diverse, cosmopolitan family of digenetic trematodes containing 47 genera and more than 400 species [1, 2]. Adult dicrocoeliids typically parasitize the bile ducts and gall-bladder of various amniotic vertebrates, but may rarely inhabit other organs $[1,3]$. This group of digeneans includes parasites of livestock and humans causing dicrocoeliasis (Dicrocoelium spp.), eurytremiasis (Eurytrema spp.) and platynosomiasis (Platynosomum spp.) [4-7]. In her latest revision of the family, Pojmańska [3] distinguished four subfamilies based on the relative position of gonads, vitellarium and uterus. The dicrocoeliid systematics is very complicated and controversial due to their high phenotypic plasticity, morphological homogeneity across multiple genera, poor descriptions and improper fixation of specimens $[1,8-10]$. Therefore, DNA sequence data from the nuclear or mitochondrial genome provide a complementary or alternative source of characters for the diagnostics and taxonomy of the Dicrocoeliidae.

Until recently, molecular phylogenetic studies included only a few representatives of the Dicrocoeliidae [11, 12], although the situation has been changing lately with a greater number of dicrocoeliid taxa being included in such analyses $[1,7,10,13-15]$. Among other systematic and nomenclatural changes, the molecular results have demonstrated the non-monophyletic nature of the majority of dicrocoeliid subfamilies, which resulted in the abandonment of the subfamily-based structure of the family [1].

The majority of the previously published molecular phylogenetic studies were based on partial sequences of the nuclear large ribosomal subunit gene (28S rDNA) which has also been used for similar studies in a broad diversity of other digenean taxa $[12,16,17]$. Therefore, in the present study, we obtained $28 \mathrm{~S}$ rDNA sequences from three avian dicrocoeliids belonging to three different genera (Brachylecithum, Brachydistomum and Lyperosomum) from Pakistan in order to establish their phylogenetic affinities within the family. Although $28 \mathrm{~S}$ sequences proved to be useful for phylogenetic inference and in some cases provided phylogenies congruent with those resulting from the analyses based on mitochondrial (mt) genomes [18] within digenean families or even superfamilies, the use of a single, relatively conserved nuclear DNA marker may not be sufficient for analysis of interrelationships among closely related taxa [18]. Therefore, additional molecular markers with greater variability are needed to evaluate the genetic relationships at this taxonomic level.

Mitochondrial genomes have been proven to be a useful source of genetic markers for taxonomic identification, studies of inter- and intra-specific variation as well as systematics and phylogenetic analysis of trematodes at different taxonomic levels including members of the Dicrocoeliidae $[19,20]$. Although molecular phylogenetic analyses based on complete $\mathrm{mt}$ genomes from multiple taxa within the Dicrocoeliidae are not yet available, mt genomes of three dicrocoeliids, Dicrocoelium chinensis, D. dendriticum and Eurytrema pancreaticum (all parasitic in mammals) have been published recently $[19,20]$. In the present study, the complete mt genome of Lyperosomum longicauda Rudolphi, 1809 (the typespecies of the genus) and nearly complete mitogenomes of Brachydistomum sp. and Brachylecithum sp. were sequenced and annotated. We used these mt genomes for comparison with other mammalian dicrocoeliids and for a broader phylogenetic analysis including other selected trematode taxa.

\section{Methods \\ Parasite collection and genomic DNA isolation}

Multiple specimens of adult dicrocoeliids were collected from the gall-bladder and bile ducts of different birds in the Swabi District, Khyber Pakhtunkhwa Province, Pakistan. Fifteen specimens of $L$. longicauda were obtained from the house crow Corvus splendens Vieillot and the rufous treepie Dendrocitta vagabunda (Latham), five specimens of Brachydistomum sp. from the robin accentor Prunella rubeculoides (Moore) and 100 specimens of Brachylecithum sp. from the shikra Accipiter badius Gmelin. Live specimens were killed with hot water and preserved in $80 \%$ ethanol [21]. The specimens for light microscopy examination were stained with alum carmine following the recommended protocol [21] and identified morphologically to the species- or genus-level (Additional file 1: Figure S1) based on identification keys and descriptions [3, 22, 23]. To confirm the taxonomic identity, genomic DNA of a single individual of each species was extracted following the protocol described by Gasser et al. [24], using the Wizard ${ }^{\circledR}$ SV Genomic DNA Purification System (Promega, Madison, USA) according to the manufacturer's instructions. For L. longicauda, genomic 
DNA was extracted from two adult parasites, one from each species of host.

\section{Amplification and analysis of nuclear 28S rDNA}

An approximately $1300 \mathrm{bp}$ long fragment at the $5^{\prime}$-end of the $28 \mathrm{~S}$ gene of three avian dicrocoeliid species was amplified, as described in previous studies [1, 15] using the primers LSU5 and 1500R [12,25] with an annealing temperature of $55{ }^{\circ} \mathrm{C}$. For L. longicauda, DNA of two specimens (one from each host species) was used for the amplification of $28 \mathrm{~S}$ gene in order to ensure that different isolates of the same species are identical. PCR products were purified with EZNA Gel Extraction Kit (OMEGA Bio-tek Inc., Doraville, GA, USA). Purified PCR products were sent to Genewiz Company (Beijing, China) for sequencing. Contiguous nucleotide sequences were assembled using DNAstar v7.1 [26] and Clustal X 1.83 [27] softwares and deposited in the GenBank database under the accession numbers MK685270, MK685272 and MK685269 for L. longicauda, Brachydistomum sp. and Brachylecithum sp., respectively.

To assess the phylogenetic interrelationships of our specimens within the Dicrocoeliidae, the newly generated $28 \mathrm{~S}$ rDNA sequences were aligned with the matching sequences of 20 dicrocoeliid species available in GenBank using MEGA7 [28]. Encyclometra colubrimurorum was used as the outgroup based on the results of previous analyses $[1,12]$. The trimmed sequences were 1175 bp long, including only a few gaps (1-3 nucleotides each). Phylogenetic analysis was conducted using the Bayesian inference (BI) method as implemented in MrBayes Ver. 3.2.6 [29]. Based on the Akaike's information criterion, GTR $+\mathrm{I}+\mathrm{G}$ was identified as the best-fitting model using jModelTest 2 software [30]. BI was conducted as follows: two Metropolis-coupled Markov chain Monte Carlo (MCMC) chains were run for 10,000,000 generations, the first $25 \%$ trees were treated as 'burn-in' and the final $75 \%$ of trees were used for calculating Bayesian posterior probabilities. The phylograms were visualized in FigTree ver. 1.4 software [31] and annotated in Adobe Illustrator ${ }^{\circledR}$.

\section{Long-PCR-based sequencing of $\mathrm{mt}$ genomes}

Degenerate primer pairs were designed based on relatively conserved regions of the mtDNA sequences of $D$. chinensis, D. dendriticum [19] and E. pancreaticum [20] and used to amplify the mitogenomes of three dicrocoelids (Additional file 2: Table S1). The complete mt genome of $L$. longicauda and the nearly complete $\mathrm{mt}$ genomes of Brachydistomum sp. and Brachylecithum sp. (excluding trnG, NCRs and trnE) were amplified in five or six overlapping fragments. Long PCR reactions were performed in reaction mixtures of $28 \mu \mathrm{l}$, containing $12.5 \mu \mathrm{l}$
$\mathrm{ddH}_{2} \mathrm{O}, 12.5 \mu \mathrm{l}$ PrimeStar Max DNA polymerase premix (Takara, Dalian, China), $1 \mu \mathrm{l}$ (10-40 ng) of template DNA and $1 \mu \mathrm{l}(25 \mu \mathrm{M})$ of each primer. PCR cycling conditions were as follows: $98{ }^{\circ} \mathrm{C}$ for $2 \mathrm{~min}$; 10 cycles of $92{ }^{\circ} \mathrm{C}$ for $10 \mathrm{~s} ; 50-57{ }^{\circ} \mathrm{C}$ for $30 \mathrm{~s} ; 68{ }^{\circ} \mathrm{C}$ for $1 \mathrm{~min} / \mathrm{kb}$ followed by $92{ }^{\circ} \mathrm{C}$ for $2 \mathrm{~min}$; 22 cycles of $92{ }^{\circ} \mathrm{C}$ for $10 \mathrm{~s} ; 50-57{ }^{\circ} \mathrm{C}$ for $30 \mathrm{~s} ; 68^{\circ} \mathrm{C}$ for $1 \mathrm{~min} / \mathrm{kb}$ and a final extension for $10 \mathrm{~min}$ at $68{ }^{\circ} \mathrm{C}$. Positive amplicons were sequenced at Genewiz sequencing company.

\section{mtDNA sequence assembly, annotation and analyses}

After quality-proofing and BLASTn analysis, the three mtDNA genomes were manually assembled with the aid of DNAstar v7.1 program [26] and further aligned with published dicrocoeliid mitogenomes: mtDNA of Brachydistomum sp. and Brachylecithum sp. were aligned with the complete mt genome of D. chinensis (GenBank: KF318786) while $L$. longicauda mtDNA was aligned with that of E. pancreaticum (GenBank: KP241855) using MAFFT Ver 7.122 [32] to determine genome organization and approximate gene boundaries. The selection of reference mitogenomes was based on the published phylogenetic relationships among dicrocoeliids [1, 15]. Protein-coding genes (PCGs) and the two mt ribosomal RNAs ( $r r n L$ and $r r n S$ ) were identified via comparison with homologs using MAFFT Ver 7.122. The size and secondary structures of transfer RNAs (tRNAs) were identified using ARWEN [33] and MITOS [34] or by pairwise comparisons with previously annotated dicrocoeliid mitogenomes. The annotations of each mitogenome were saved as text documents which were further processed in PhyloSuite v1.1.14 [35] in order to generate the NCBI submission file (".sqn), tables of comparisons and statistics for mitogenomes. The same software was used to translate the nucleotide sequences of 12 mitochondrial PCGs into amino acids and to calculate codon usage and relative synonymous codon usage (RSCU) for the 12 PCGs. The codon usage and RSCU for 12 PCGs of the six dicrocoeliid mitogenomes (three newly sequenced avian and three previously published mammalian) were computed and used to draw the RSCU figure using the ggplot2 [36] plugin of PhyloSuite.

Mutation rate (non-synonymous/synonymous, $\mathrm{dN} / \mathrm{dS}$ ) ratios among the 12 PCGs of the three newly sequenced dicrocoeliid mitogenomes were calculated using DnaSP v.5 [37]. DnaSP v.5 was also used to conduct sliding window analysis implementing window size of $300 \mathrm{bp}$ and a step size of $30 \mathrm{bp}$, to estimate the nucleotide divergence between 12 PCGs, two rRNAs and 20 tRNAs (excluding $\operatorname{trn} G$ and $\operatorname{trn} E$ ) of the six dicrocoeliid mitogenomes. The nucleotide contents of dicrocoeliid mitogenomes were compared with other families of the suborder Xiphidiata using PhyloSuite; the resulting files were further used to 
make the line plots of $\mathrm{A}+\mathrm{T}$ content in ggplot2. Tandem Repeats Finder [38] and mreps [39] were used to find the tandem repeats (TRs) within the NCRs of complete mitogenome of $L$. longicauda. The secondary structures of TRs were predicted using Mfold software [40].

\section{Phylogenetic relationships of the Dicrocoeliidae with other digeneans}

Phylogenetic analyses were conducted using all six dicrocoeliid mitogenomes and mitogenomes of 20 other digeneans from the suborder Opisthorchiata La Rue, 1957, Pronocephalata Olson, Cribb, Tkach, Bray \& Littlewood, 2003, Xiphidiata Olson, Cribb, Tkach, Bray \& Littlewood, 2003 and Echinostomata La Rue, 1926. A species belonging to the order Diplostomida, Schistosoma japonicum, was used as the outgroup. The nucleotide sequences of 12 PCGs, 2 rRNAs, and 20 tRNAs (trnG and trnE were excluded from analyses, as these two tRNAs were not sequenced for two out of three species) of all included mitogenomes were obtained from GenBank files using PhyloSuite [35]. Phylogenetic analyses were conducted using codon-based alignment of nucleotide sequences of 12 PCGs + Q-INS-i strategy of alignment for rRNAs and tRNAs. Nucleotide sequences of each gene were aligned in batches using MAFFT Ver 7.122, ambiguously aligned regions were deleted using Gblocks 0.91b [41]; sequences were subsequently concatenated into a single alignment used to generatehttps://eproofing.springer. com/journals_v2/index.php?token=GsTHfr8z9G_W7jV7z5wzAQrcLzIrKUUYWq59wmNCH8k nexus files in PhyloSuite. Phylogenetic analyses were performed using maximum likelihood (ML) and BI methods. Based on the Akaike's information criterion, as implemented in ModelFinder [42], GTR+F+R5 and GTR+F+I+G4 were chosen as best-fitting models for nucleotide evolution for the ML and BI analysis, respectively. ML phylogenies were inferred using IQ-TREE [43] by performing ultrafast bootstraps [44] with 5000 replicates. BI phylogenies were inferred using MrBayes 3.2.6 [29] (with default settings) using two MCMC chains for 3,000,000 generations and 1000 sample frequency; the initial 25\% (750) trees were discarded as 'burn-in'. In addition, in order to remove effects of possible mutation saturation due to silent mutations we have performed a phylogenetic analysis based on alignment of translated sequences of 12 PCGs. This phylogeny was inferred using Jones $+\mathrm{I}+\mathrm{G}+\mathrm{F}$ model ( 2 parallel runs, 1,000,000 generations) using the same software and procedures as described above for the nucleotidebased phylogeny. Finally, phylograms were visualized and annotated by iTOL [45] and Adobe Illustrator ${ }^{\circledR}$ with the aid of dataset files generated by PhyloSuite.

\section{Results and discussion}

Molecular phylogeny within the Dicrocoeliidae based on $28 \mathrm{~S}$ rDNA sequences

The sequenced region of the $28 \mathrm{~S}$ gene was $1323 \mathrm{bp}$ long for L. longicauda, 1274 bp for Brachylecithum sp. and $1371 \mathrm{bp}$ for Brachydistomum sp. Sequences of two isolates of $L$. longicauda were identical. Bayesian analysis based on partial $28 \mathrm{~S}$ rDNA placed our specimens close to other members of the three corresponding genera, i.e. Lyperosomum Looss, 1899; Brachydistomum Travassos, 1944 and Brachylecithum Shtrom, 1940 thus providing additional confirmation of their identifications. The analysis placed L. longicauda (the type-species) close to Lyperosomum collurionis (Skrjabin \& Isaichikov, 1927) with maximum nodal support $(\mathrm{bpp}=1)$ in a clade also containing Platynosomum illiciens (Braun, 1901) and E. pancreaticum (Janson, 1889) (Fig. 1). Our specimens identified as Brachydistomum sp. grouped together with Brachydistomum ventricosum (Rudolphi, 1802) $(\mathrm{bpp}=1)$ in a clade that also contained species of Dicrocoelium Dujardin, 1845. The clade containing Brachylecithum grummti Odening, 1964 and Brachylecithum sp. (present study) appeared close $(\mathrm{bpp}=0.96)$ to the clade containing species of Dicrocoelium and Brachydistomum and was not closely related to the remaining members of Brachylecithum in the tree, namely the clades $B$. lobatum Railliet, $1900+B$. capilliformis Oshmarin, 1952 and B. kakea Bhalerao, 1926+ B. laniicola Layman, 1926. Recent studies documented the paraphyletic nature of the genus Brachylecithum [1, 15]. Tkach et al. [1] suggested that $B$. grummti likely represents a separate genus, but underlined that formally establishing this new genus requires a thorough additional morphological analysis. Our study added an additional species to the B. grummti clade thus potentially strengthening the case for establishing a new genus and providing additional molecular and morphological evidence.

\section{Gene organization, size and nucleotide content of mitogenomes}

The complete circular mt genome of L. longicauda was 14,567 bp (GenBank: MK685274) while the nearly complete mitogenome of Brachydistomum sp. was 13,353 bp (GenBank: MK685273) and of Brachylecithum sp. was 13,275 bp (GenBank: MK685271) in size. We failed to obtain high quality sequences of the non-coding regions and two tRNAs (trnE and $\operatorname{trn} G$ ) of the $\mathrm{mt}$ genomes of Brachylecithum sp. and Brachydistomum sp., most likely due to the presence of multiple regions of repetitive motifs which terminated sequencing. Similar regions in other studies of $\mathrm{mt}$ genomes have also been shown as problematic [46, 47]. Therefore, the PacBio 


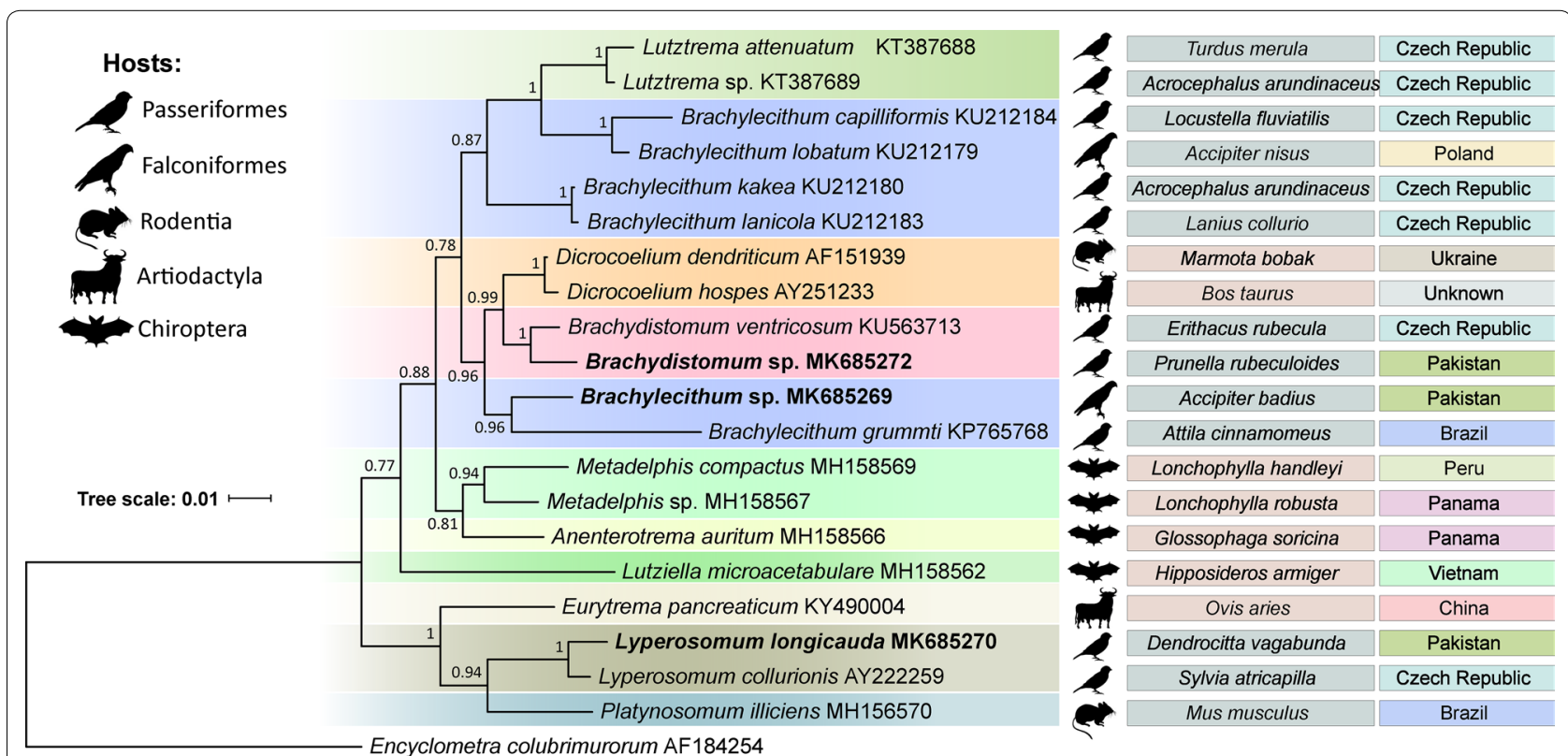

Fig. 1 Phylogenetic interrelationships among 20 dicrocoeliids resulting from Bayesian inference (BI) analysis using partial 28S rDNA sequences. Node labels indicate posterior probabilities (> 70\%). Host groups, name and geographical regions are shown to the right from each digenean taxon. The newly generated sequences are indicated in bold. Encyclometra colubrimurorum was used as the outgroup

single-molecule real-time sequencing method has been used by researchers in recent studies to characterize long and difficult to sequence repetitive regions of flatworm mitogenomes [48, 49]. Nonetheless, the coding regions of the mt genomes of Brachylecithum sp. and Brachydistomum sp. sequenced in the present study were sufficient for the characterization of their $\mathrm{mt}$ genomes and phylogenetic implications. The gene order of all three newly sequenced dicrocoeliid $\mathrm{mt}$ genomes was identical to that of previously published dicrocoeliids and several other digeneans including xiphidiatans (Paragonimus spp.). The nucleotide composition in dicrocoeliid $\mathrm{mt}$ genomes showed a significant bias toward $\mathrm{T}$. The overall $\mathrm{A}+\mathrm{T}$ content in the $\mathrm{mt}$ genomes of L. longicauda, Brachydistomum sp. and Brachylecithum sp. was $62.1 \%$, $63.1 \%$ and $62.6 \%$, respectively. This is very close to the proportions seen in D. chinensis $(62.11 \%)$, D. dendriticum $(62.18 \%)$ and E. pancreaticum (62.50\%). Interestingly, all six dicrocoeliid $\mathrm{mt}$ genomes have a higher $\mathrm{A}+\mathrm{T}$ content in their individual genes, each codon position (1st, 2nd and 3rd) and the entire mt genome than other xiphidiatans with published mitogenomes, e.g. Brachycladium goliath (55.6\%) (Brachycladiidae), Paragonimus heterotremus (58.4\%) and Paragonimus westermani (51.7\%) (Paragonimidae) (Fig. 2).

\section{Protein-coding genes and codon usage}

Concatenated 12 PCGs were 10,126 bp, 10,154 bp and 10,160 bp in size, with A $+\mathrm{T}$ contents being $62.9 \%, 64.1 \%$ and $63.6 \%$ in mt genomes of L. longicauda, Brachydistomum sp. and Brachylecithum sp., respectively (Additional file 3: Table S2). ATG and GTG were the most common start codons for 12 PCGs of three studied avian dicrocoeliid $\mathrm{mt}$ genomes with exception of the nad2 and $\operatorname{cox} 1$ of the Brachylecithum sp. which used TTG as the start codon. The start codon TTG for the PCGs was observed in the mitogenomes of many other flatworms, for example the nad1, cytb, nad2 and cox1 of Sindiplozoon sp. [50], the nad5 of Fasciola sp. [51] and cytb and nad5 of D. chinensis and D. dendriticum [19]. Most of the 12 PCGs used the standard TAG or TAA or the abbreviated $\mathrm{T}$ as translation stop codons (Table 1 ). Codon usage and RSCU of the six available dicrocoeliid mitogenomes showed a high proportion of amino acids encoded by guanine and thymine-rich codons (such as Val, Phe, Leu2 and Gly) compared to those encoded by adenosine and cytosine-rich codons (such as Gln, Lys and His). However, there were no significant differences in the proportion of amino acids used for the construction of 12 PCGs across six available dicrocoeliid mitogenomes (Additional file 4: Figure S2).

\section{Transfer and ribosomal RNA genes}

Twenty-two transfer RNA (tRNA) genes were found in the complete $\mathrm{mt}$ genome of $L$. longicauda and 20 (excluding $\operatorname{trn} G$ and $\operatorname{trn} E$ ) were found in the nearly complete $\mathrm{mt}$ genomes of Brachydistomum sp. and Brachylecithum sp. Their total concatenated length was $1434 \mathrm{bp}, 1320 \mathrm{bp}$ 


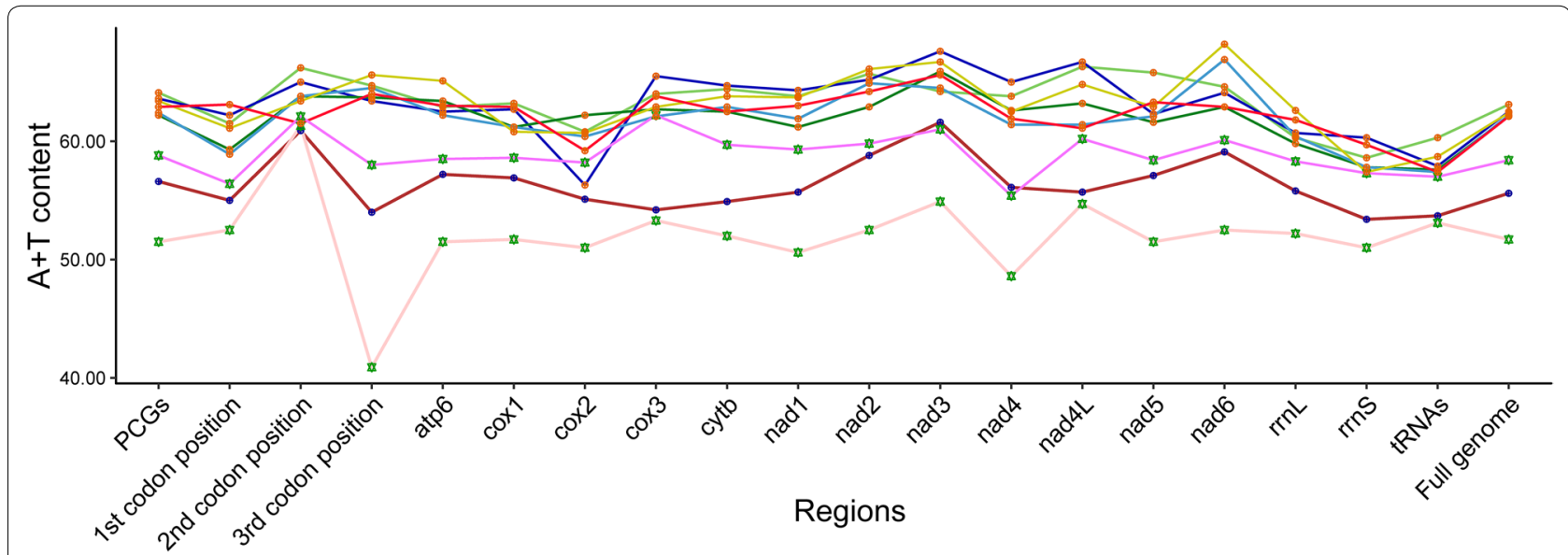

Family $\oplus$ Brachycladiidae $\oplus$ Dicrocoeliidae $\not$ Paragonimidae

$$
\text { Species - Brachycladium goliath - Brachylecithum sp. - Dicrocoelium dendriticum - Lyperosomum longicauda - Paragonimus westermani }
$$

Fig. $2 \mathrm{~A}+\mathrm{T}$ content (\%) of genes, each codon position of PCGs and complete or nearly complete mitochondrial genomes of the three newly sequenced samples in this study and other xiphidiatans downloaded from GenBank. Line color and symbols indicate xiphidiatan species and families, respectively

and 1273 bp for L. longicauda, Brachydistomum sp. and Brachylecithum sp., respectively. All tRNA genes had the standard anticodons observed in other flatworms, with the exception of trnS1 in Brachydistomum sp. and trnK in Brachylecithum sp. where anticodon TCT was found for trnS1 and TTT for trnK. This modification of anticodons, supposedly a homoplasy [50], from GCT to TCT (in trnS1) and CTT to TTT (in $\operatorname{trnK}$ ) was also found in some other flatworms, e.g. Hypoderaeum conoideum (Trematoda: Echinostomatidae) [52] and Khawia sinensis (Cestoda: Caryophyllidea) [53]. The secondary structures of tRNAs were similar to those in the corresponding genes in E. pancreaticum [20]; all tRNAs except for trnS1 (AGN) and trnS2 (UCN), could be folded into the typical cloverleaf secondary structure. Similar to other dicrocoeliids, the two ribosomal RNA genes ( $r r n L$ and $r r n S)$ in the species examined in our study, were located between $\operatorname{trn} T$ and $\operatorname{cox} 2$ for each species. The $\mathrm{A}+\mathrm{T}$ content in the $r r n L$ gene (60.3-61.8\%) was higher than in the $r r n S$ gene (58.6-60.3\%) across all three species.

\section{Non-coding regions}

The complete $\mathrm{mt}$ genome of $L$. longicauda contained two non-coding regions (NCRs); a short non-coding region (SNCR) (398 bp) located between $\operatorname{trn} G$ and $\operatorname{trn} E$ and a long non-coding region (LNCR) (769 bp) located between trnE and cox3. Both NCRs were located in the same position as in the previously published mitogenomes of mammalian dicrocoeliids. The LNCR of $L$. longicauda $\mathrm{mt}$ genome contained three sets of identical tandem repeats (TRs); two 80 bp long tandem repeats and one 36 bp long tandem repeat. The SNCR lacks any tandem repeat sequences, but is capable of forming a stem-looped structure like that of tandem repeats of LNCR, as predicted by Mfold (Additional file 5: Figure S3). The A + T content in SNCR (68.3\%) of L. longicauda $\mathrm{mt}$ genome is higher than that in LNCR (62.8\%).

\section{Sliding window analysis and nucleotide diversity among dicrocoeliid mitogenomes}

The sliding window analysis was conducted using an alignment of concatenated mt PCGs, rRNAs and tRNAs (except $\operatorname{trn} G$ and $\operatorname{trnE}$ ) of all six dicrocoeliid mitogenomes to determine the most conserved and most variable genes. The plot revealed a high nucleotide diversity among six mitogenome sequences with Pi values ranging from 0.144 to 0.449 (window size $=200 \mathrm{bp}$, step size $=20)$. Genes with relatively high sequence variability included atp6 (0.382), nad5 (0.368), nad3 (0.364) and nad2 (0.353), while cox 1 and cytb (0.215), rrnS (0.226), $r r n L$ (0.229), tRNAs (0.247) and nad1 (0.248) showed relatively lower sequence variability (Fig. 3a). Similarly, atp6 had the highest Kimura-2-parameter (K2P) genetic distance across the 12 PCGs among the six dicrocoeliid mitogenomes, followed by nad5 and nad3 (Fig. 3b).

This was further corroborated by the average sequence identity (Table 1 ) and $\mathrm{dN} / \mathrm{dS}$ ratio analysis among the 12 PCGs of the three newly obtained 
Table 1 Comparison of the annotated mitochondrial genomes of Brachydistomum sp., Brachylecithum sp. and Lyperosomum longicauda

\begin{tabular}{|c|c|c|c|c|c|c|c|}
\hline Gene/region & Position $\left(5^{\prime}-3^{\prime}\right)$ & & Length (bp) & Start codon & Stop codon & Anti-codon & Identity (\%) \\
\hline Brachydistome & um sp./Brachylecithum & sp./Lyperosomum longi & icauda & & & & $\mathrm{Bd}-\mathrm{BI} / \mathrm{Bd}-\mathrm{LI} / \mathrm{BI}-\mathrm{LI} / \mathrm{A}$ \\
\hline $\operatorname{cox} 3$ & $1 / 1 / 1$ & $651 / 651 / 645$ & $651 / 651 / 645$ & ATG/ATG/ATG & TAA/TAG/TAA & & $78.34 / 62.98 / 64.82 / 68.71$ \\
\hline $\operatorname{trnH}$ & 691/661/663 & 764/723/729 & $74 / 63 / 67$ & & & GTG/GTG/GTG & $55.41 / 51.35 / 75.36 / 60.71$ \\
\hline cytb & 768/724/733 & 1886/1833/1848 & 1119/1110/1116 & ATG/GTG/ATG & $\mathrm{TAG} / \mathrm{TAG} / \mathrm{TAG}$ & & 79.54/77.39/76.97/77.97 \\
\hline nad4L & $1891 / 1826 / 1849$ & $2160 / 2089 / 2118$ & $270 / 264 / 270$ & ATG/ATG/GTG & TAA/TAA/TAA & & $72.59 / 62.64 / 67.40 / 67.54$ \\
\hline nad4 & $2121 / 2050 / 2082$ & $3389 / 3318 / 3365$ & $1269 / 1269 / 1284$ & ATG/ATG/GTG & $\mathrm{TAG} / \mathrm{TAG} / \mathrm{TAG}$ & & $69.74 / 62.55 / 66.05 / 66.11$ \\
\hline $\operatorname{trn} Q$ & $3397 / 3329 / 3375$ & $3458 / 3391 / 3436$ & $62 / 63 / 62$ & & & TTG/TTG/TTG & 84.13/76.19/77.78/79.37 \\
\hline $\operatorname{trnF}$ & $3462 / 3394 / 3440$ & $3523 / 3456 / 3504$ & $62 / 63 / 65$ & & & GAA/GAA/GAA & $95.24 / 81.82 / 81.82 / 86.29$ \\
\hline $\operatorname{trn} M$ & $3524 / 3457 / 3503$ & $3584 / 3517 / 3565$ & $61 / 61 / 63$ & & & CAT/CAT/CAT & $96.72 / 74.60 / 74.60 / 81.98$ \\
\hline atp6 & $3585 / 3518 / 3566$ & $4094 / 4027 / 4084$ & $510 / 510 / 519$ & ATG/ATG/ATG & TAA/TAG/TAG & & $58.91 / 57.36 / 54.78 / 57.02$ \\
\hline nad2 & $4101 / 4028 / 4091$ & 4967/4900/4963 & $867 / 873 / 873$ & ATG/TTG/ATG & TAG/TAG/TAG & & $65.29 / 60.54 / 58.59 / 61.48$ \\
\hline $\operatorname{trn} V$ & $4985 / 4913 / 4974$ & $5048 / 4976 / 5043$ & $64 / 64 / 70$ & & & TAC/TAC/TAC & 75.38/81.43/74.29/77.03 \\
\hline $\operatorname{trn} A$ & $5055 / 4980 / 5050$ & $5122 / 5041 / 5115$ & $68 / 62 / 66$ & & & TGC/TGC/TGC & 73.53/73.53/74.24/73.77 \\
\hline $\operatorname{trn} D$ & $5132 / 5045 / 5116$ & $5200 / 5111 / 5184$ & $69 / 67 / 69$ & & & GTC/GTC/GTC & $77.14 / 68.06 / 71.01 / 72.07$ \\
\hline nad1 & $5202 / 5113 / 5185$ & $6108 / 6016 / 6090$ & 907/904/906 & GTG/GTG/ATG & T/T/TAA & & $75.52 / 71.40 / 70.63 / 72.52$ \\
\hline $\operatorname{trn} N$ & $6109 / 6020 / 6103$ & $6174 / 6083 / 6171$ & $66 / 64 / 69$ & & & GTT/GTT/GTT & $69.12 / 75.36 / 69.57 / 71.35$ \\
\hline $\operatorname{trn} P$ & $6184 / 6098 / 6177$ & $6254 / 6163 / 6249$ & $71 / 66 / 73$ & & & TGG/TGG/TGG & $64.79 / 63.64 / 67.12 / 65.18$ \\
\hline $\operatorname{trnl}$ & $6270 / 6164 / 6256$ & $6334 / 6227 / 6321$ & $65 / 64 / 66$ & & & GAT/GAT/GAT & 80.00/83.33/74.24/79.19 \\
\hline $\operatorname{trnK}$ & $6344 / 6244 / 6333$ & 6410/6310/6399 & $67 / 67 / 67$ & & & CTT/TTT/CTT & $65.71 / 67.14 / 65.22 / 66.02$ \\
\hline nad3 & $6411 / 6310 / 6402$ & 6759/6658/6747 & $349 / 349 / 346$ & ATG/GTG/GTG & $\mathrm{T} / \mathrm{T} / \mathrm{T}$ & & $60.74 / 57.31 / 65.90 / 61.32$ \\
\hline $\operatorname{trnS1}$ & $6760 / 6659 / 6748$ & $6818 / 6718 / 6804$ & $59 / 60 / 57$ & & & TCT/GCT/GCT & $65.00 / 66.10 / 75.00 / 68.70$ \\
\hline $\operatorname{trn} W$ & $6850 / 6721 / 6806$ & $6914 / 6780 / 6870$ & $65 / 60 / 65$ & & & TCA/TCA/TCA & 70.77/81.54/69.23/73.85 \\
\hline $\operatorname{cox} 1$ & $6923 / 6784 / 6891$ & $8479 / 8334 / 8438$ & 1557/1551/1548 & ATG/TTG/ATG & TAG/TAG/TAG & & 79.77/75.21/79.13/78.04 \\
\hline $\operatorname{trn} T$ & $8502 / 8376 / 8451$ & $8564 / 8437 / 8518$ & $63 / 62 / 68$ & & & TGT/TGT/TGT & $70.77 / 69.12 / 66.67 / 68.85$ \\
\hline$r r n L$ & $8567 / 8439 / 8519$ & $9546 / 9414 / 9508$ & 980/976/990 & & & & $77.36 / 73.69 / 74.00 / 75.02$ \\
\hline $\operatorname{trn} C$ & $9547 / 9415 / 9509$ & $9612 / 9477 / 9570$ & $66 / 63 / 62$ & & & GCA/GCA/GCA & $80.30 / 74.24 / 73.02 / 75.85$ \\
\hline$r r n S$ & $9613 / 9478 / 9571$ & 10324/10226/10304 & 712/749/734 & & & & $74.74 / 68.18 / 72.35 / 71.76$ \\
\hline $\cos 2$ & 10325/10227/10305 & 10957/10865/10895 & 633/639/591 & ATG/ATG/ATG & TAG/TAG/TAG & & $56.99 / 62.11 / 58.07 / 59.06$ \\
\hline nad6 & $10964 / 10879 / 10916$ & 11413/11340/11365 & $450 / 462 / 450$ & GTG/ATG/ATG & TAG/TAG/TAG & & $59.05 / 64.44 / 65.52 / 63.00$ \\
\hline $\operatorname{trn} Y$ & $11416 / 11346 / 11366$ & $11488 / 11407 / 11428$ & $73 / 62 / 63$ & & & GTA/GTA/GTA & $58.90 / 65.75 / 61.54 / 62.07$ \\
\hline $\operatorname{trn} L 1$ & 11497/11408/11433 & 11560/11474/11495 & $64 / 67 / 63$ & & & TAG/TAG/TAG & $52.17 / 69.23 / 69.12 / 63.51$ \\
\hline $\operatorname{trnS2}$ & $11566 / 11480 / 11497$ & $11634 / 11543 / 11562$ & $69 / 64 / 66$ & & & TGA/TGA/TGA & $47.83 / 62.86 / 55.22 / 55.30$ \\
\hline $\operatorname{trn} L 2$ & 11639/11549/11564 & $11702 / 11612 / 11629$ & $64 / 64 / 66$ & & & TAA/TAA/TAA & $73.85 / 74.24 / 76.12 / 74.74$ \\
\hline $\operatorname{trn} R$ & $11711 / 11629 / 11634$ & 11778/11695/11694 & $68 / 67 / 61$ & & & TCG/TCG/TCG & $54.93 / 57.35 / 52.24 / 54.84$ \\
\hline nad5 & 11782/11698/11697 & 13353/13275/13274 & 1572/1578/1578 & GTG/ATG/ATG & TAA/TAG/TAA & & $64.50 / 60.23 / 60.45 / 61.73$ \\
\hline $\operatorname{trn} G$ & $-/-/ 13277$ & $-/-/ 13340$ & $-/-/ 64$ & & & $-/-/ \mathrm{TCC}$ & \\
\hline SNCR & $-/-/ 13341$ & $-/-/ 13738$ & $-/-/ 398$ & & & & \\
\hline $\operatorname{trn} E$ & $-/-/ 13739$ & $-/-/ 13800$ & $-/-/ 62$ & & & $-/-/ \mathrm{TTC}$ & \\
\hline LNCR & $-/-/ 13801$ & $-/-/ 14567$ & $-/-/ 767$ & & TAA/TAG/TAA & & \\
\hline
\end{tabular}

Abbreviations: Bd, Brachydistomum sp.; Bl, Brachylecithum sp.; LI, Lyperosomum longicauda; A, average identity values (\%) of the three dicrocoeliids

dicrocoeliid mitogenomes. These analyses produced similar results where the average sequence identity was the highest across cox1 (78.04\%), cytb (77.97\%) and nad 1 (72.52\%) and the lowest across atp6 (57.02\%), cox2 (59.06\%), nad3 (61.32\%), nad2 (61.48\%) and nad5 (61.73\%). Likewise, the highest non-synonymous substitution rate $(\mathrm{dN})$ was observed in atp6, while cox 1 had the lowest $\mathrm{dN}$ value of the 12 PCGs (Fig. 4).

Thus, our analyses showed the comparatively fast mutation rate of atp6, nad5, nad 3 and nad 2 while cox1, $c y t b$ and nad 1 are evolving comparatively slowly in the Dicrocoeliidae. Although cox $1, c y t b, \operatorname{nad} 1$ and two $\mathrm{mt}$ 


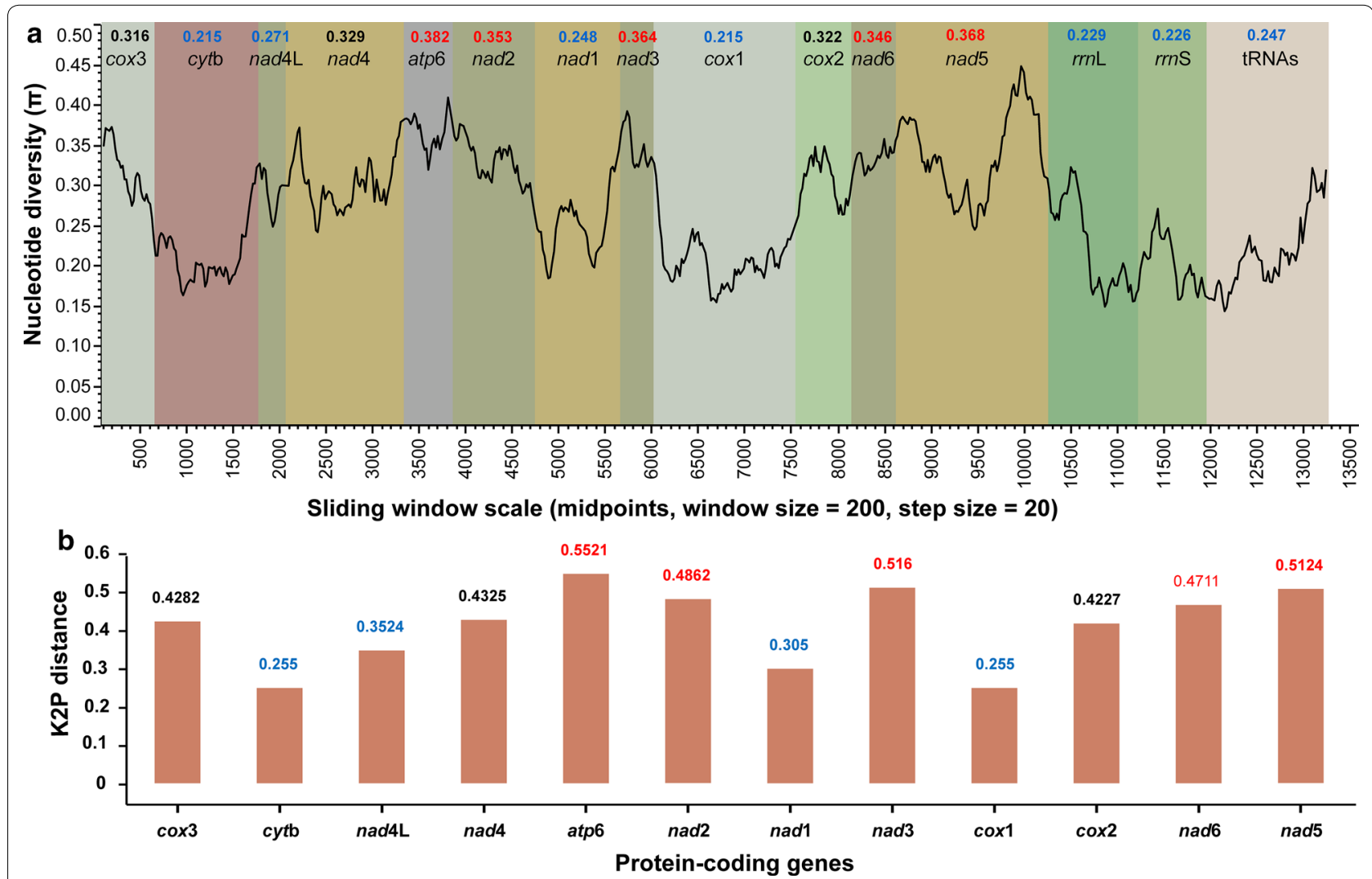

Fig. 3 Genetic analyses among six dicrocoeliid mitogenomes. a Sliding window analysis of the alignment of 12 protein-coding genes (PCGs), 2 rRNAs and 18 coalescent tRNAs (trnE and trnG were removed as we did not obtained their sequences for our two samples). The black line represents nucleotide variation in a window of $200 \mathrm{bp}$ (step size $=20 \mathrm{bp}$, with the value inserted at its mid-point). Gene boundaries are indicated by color with mean variation ratio per gene shown above each gene. $\mathbf{b}$ The Kimura-2-parameter distance (K2P) among 12 PCGs of dicrocoeliid mitogenomes. The highest and lowest Pi values and K2P distance are indicated by red and blue color, respectively

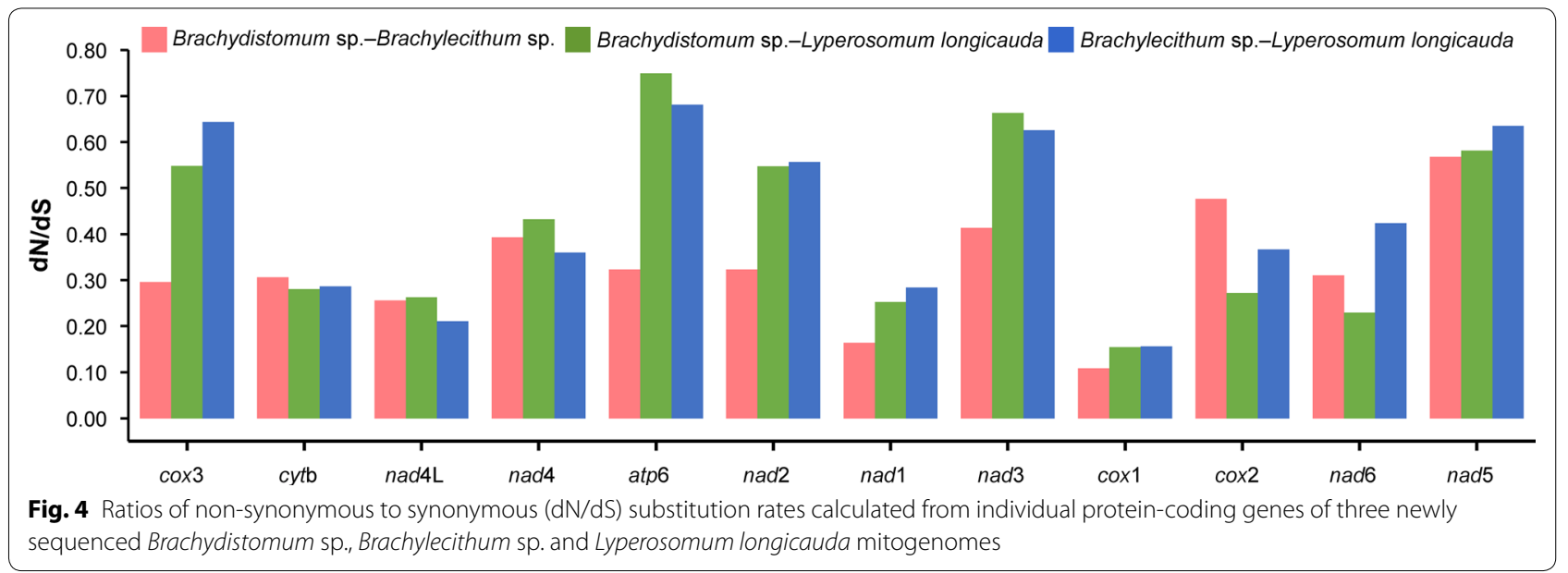

rRNAs are often used as barcodes and have been extensively used for species identification and population genetics in trematodes, we suggest that fast evolving atp6, nad5, nad 3 and nad2 would be better markers for analyzing relationships among dicrocoeliids (and likely, other digeneans) at lower taxonomic levels. Similar fastevolving mt genes have been proposed as better molecular markers for analyzing relationships among closely 
related species of other flatworms in recent studies [50, 54].

\section{Phylogeny of the Dicrocoeliidae based on mt genome sequences}

Both ML and BI analyses produced phylogenetic trees with the same branch topologies and only minor differences in statistical support values for some nodes (Fig. 5). Similarly, the phylogenetic tree based on concatenated amino acid sequences (BI analysis) of 11 PCGs was consistent with that resulted from nucleotide sequences (Additional file 6: Figure S4). The only notable difference was the position of the clade containing members of the Gastrothylacidae, Paramphistomidae, Gastrodiscidae and Notocotylidae which clustered together in a separate clade close to the clade containing members of the Opisthorchiidae, Heterophyidae, Brachycladiidae and Paragonimidae (Additional file 6: Figure S4). The position of the Dicrocoeliidae clade as well as the internal branch topology within the Dicrocoeliidae were identical in the phylogenies based on the nucleotide and amino acid sequence alignments. The general tree topology and positions of included families were consistent with previous studies based on mitogenome sequences [19, 20, 55]. The phylogenetic tree supported the monophyly of all families represented in the analysis by more than a single $\mathrm{mt}$ genome. Within the Dicrocoeliidae, all six dicrocoeliids belonging to five genera clustered together with maximum nodal support (bootstrap values $=100$ and bpp =1). The position of Brachydistomum sp. and Brachylecithum sp. was consistent with their respective placement in the present as well as in previous phylogenetic analyses based on $28 \mathrm{~S}$ rDNA sequences $[1,15]$. The tree also showed that the family Paragonimidae (represented by Paragonimus spp.) was genetically closer to the Brachycladiidae than to the Dicrocoeliidae while some of the previously published data, based on nuclear ribosomal genes, documented the close genetic relationship among the Paragonimidae and the Dicrocoeliidae, where both families were classified within the superfamily Gorgoderoidea [12].

Although discordance between phylogenies based on shorter nuclear sequences and mitogenomes is not uncommon [18], some previous phylogenetic analyses based on $28 \mathrm{~S}$ rDNA $[16,56]$ also did not support close relationships between the Paragonimidae and other families classified within the Gorgoderoidea sensu Curran, Tkach \& Overstreet, 2006. Moreover, the position of the Dicrocoeliidae in the mitogenome-based tree is also problematic since it is positioned outside the clade uniting other xiphidiatan trematodes (Brachycladiidae and Paragonimidae), thus suggesting that the content of the

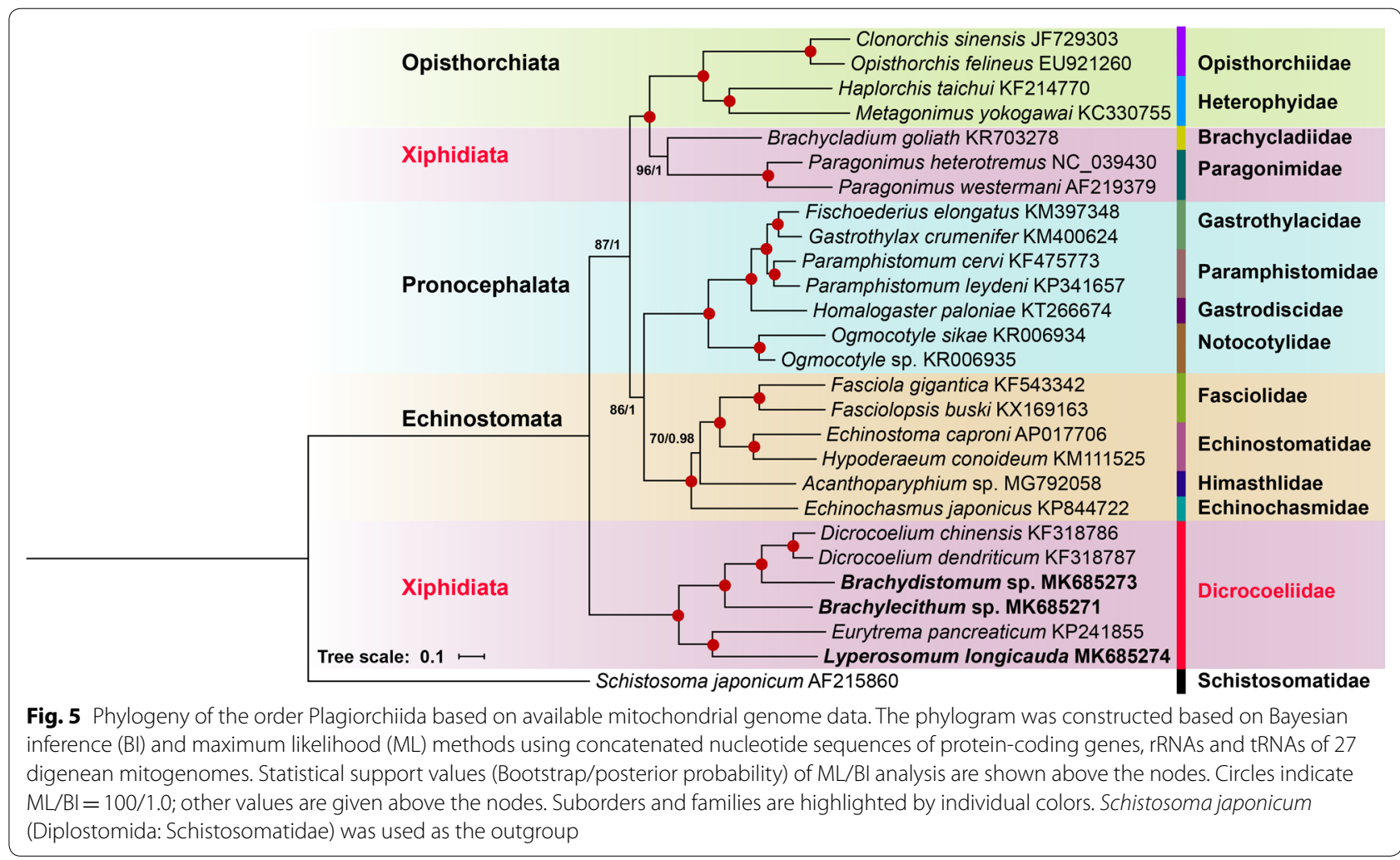


Xiphidiata as defined by Olson et al. [12] and the interrelationships between its constituent families may need to be reconsidered with more sequence data, e.g. ultraconserved elements (UCEs) [18].

\section{Conclusions}

The present study reports results of the analysis of complete, or nearly complete, mt genomes of three avian dicrocoeliids representing three genera Brachylecithum, Brachydistomum, and Lyperosomum. We analyzed phylogenetic affinities of these taxa within the family Dicrocoeliidae using partial sequences of the nuclear large ribosomal subunit (28S) RNA gene and a nearly complete set of mt genes. The phylogeny based on the $28 \mathrm{~S}$ gene provided additional evidence for the paraphyletic nature of Brachylecithum and revealed an additional sister species to B. grummti which likely represents a separate genus. Our analysis of the combined nucleotide diversity, Kimura-2-parameter distances, non-synonymous/synonymous substitutions ratios and average sequence identity among dicrocoeliid mitogenomes suggest that atp6, nad5, nad 3 and nad 2 genes are better molecular markers for differentiation and population level studies than the commonly used cox 1 and nad 1 genes for dicrocoeliids. Furthermore, the phylogenetic position of the family Dicrocoeliidae (outside the clade uniting other xiphidiatan trematodes) within the order Plagiorchiida based on all mitochondrial genes (except $\operatorname{trn} G$ and $\operatorname{trn} E$ ) cautiously suggests that the content of the Xiphidiata may need to be reconsidered with more sequence data. However, considering the high mutation rate and the possible effect of mutation saturation on the results of phylogenetic analyses at higher taxonomic levels, we abstain from suggesting systematic changes at this point.

\section{Supplementary information}

Supplementary information accompanies this paper at https://doi. org/10.1186/s13071-020-3940-7.

Additional file 1: Figure S1. Representatives of the three studied dicrocoeliid species. a Brachydistomum sp. b Brachylecithum sp. c Lyperosomum longicauda. Scale-bars: $1 \mathrm{~mm}$.

Additional file 2: Table S1. Sequences of primers used to amplify and sequence the mitochondrial genomes of Lyperosomum longicauda, Brachydistomum sp., and Brachylecithum sp.

Additional file 3: Table S2. Nucleotide composition and skewness of three newly sequenced dicrocoeliids mitochondrial genomes.

Additional file 4: Figure S2. Relative synonymous codon usage (RSCU) for the 12 protein-coding genes of six dicrocoeliids mitogenomes. Codon families are labeled on the $x$-axis. Values on the top of the bars indicate percentage of each amino acid used for the construction of 12 proteincoding genes.

Additional file 5: Figure S3. Secondary structures of the short noncoding region (SNCR) and tandem repeats (TRs) in the large non-coding regions (LNCR) in the mitogenome of Lyperosomum longicauda.
Additional file 6: Figure S4. Phylogeny of the order Plagiorchiida based on Bayesian inference (BI) using concatenated amino acid sequences of 12 mitochondrial protein-coding genes. Statistical support values (posterior probability) of BI analysis are shown above the nodes. Schistosoma japonicum (Diplostomida: Schistosomatidae) was used as the outgroup.

\section{Abbreviations}

Bl: Bayesian inference; ML: Maximum likelihood; MCMC: Metropolis-coupled Markov chain Monte Carlo; PCGs: Protein-coding genes; tRNAs: Transfer RNAs; rRNAs: Ribosomal RNAs; RSCU: Relative synonymous codon usage; dN/dS: Non-synonymous/synonymous; TRs: Tandem repeats; NCRs: Non-coding regions; SNCR: Short non-coding region; LNCR: Long non-coding region; K2P: Kimura-2-parameter.

\section{Acknowledgements}

We would like to thank Ms Rong Li (Lanzhou Veterinary Research Institute, Chinese Academy of Agricultural Sciences) for technical assistance.

\section{Authors' contributions}

$J M$, VVT and XQZ conceived and designed the study, and critically revised the manuscript. Suleman performed the experiment, analyzed the data and drafted the manuscript. MSK and NM participated in specimen collections. VVT, JM and DZ contributed to data analysis and preparation of figures. All authors read and approved the final manuscript.

\section{Funding}

This study was supported by the National Natural Science Foundation of China (Grant No. 31702225), the International Science and Technology Cooperation Project of Gansu Provincial Key Research and Development Program (Grant No. 17JR7WA031) and the Agricultural Science and Technology Innovation Program (ASTIP) (Grant No. CAAS-ASTIP-2016-LVRI-03).

\section{Availability of data and materials}

The datasets supporting the findings of this article are included within the article and its additional files. The nuclear $28 \mathrm{~S}$ rDNA nucleotide sequences generated in this study for L. longicauda, Brachydistomum sp. and Brachylecithum sp. were deposited in the GenBank database under the accession numbers MK685270, MK685272 and MK685269, respectively. The mitogenomic sequences of L. Iongicauda, Brachydistomum sp. and Brachylecithum sp. are available in GenBank under the accession numbers MK685274, MK685273 and MK685271, respectively.

\section{Ethics approval and consent to participate}

This study was conducted in accordance with the recommendations set forth in the Animal Ethics Procedures and Guidelines of the People's Republic of China. This study was reviewed and approved by the Animal Administration and Ethics Committee of Lanzhou Veterinary Research Institute, Chinese Academy of Agricultural Sciences.

\section{Consent for publication}

Not applicable.

\section{Competing interests}

The authors declare that they have no competing interests.

\section{Author details}

${ }^{1}$ State Key Laboratory of Veterinary Etiological Biology, Key Laboratory of Veterinary Parasitology of Gansu Province, Lanzhou Veterinary Research Institute, Chinese Academy of Agricultural Sciences, Lanzhou 730046, Gansu, People's Republic of China. ${ }^{2}$ Department of Zoology, University of Swabi, Swabi 23340, Khyber Pakhtunkhwa, Pakistan. ${ }^{3}$ Department of Biology, University of North Dakota, Grand Forks, ND 58202-9019, USA. ${ }^{4}$ Key Laboratory of Aquaculture Disease Control, Ministry of Agriculture, and State Key Laboratory of Freshwater Ecology and Biotechnology, Institute of Hydrobiology, Chinese Academy of Sciences, Wuhan 430072, Hubei, People's Republic of China. ${ }^{5}$ Jiangsu Co-innovation Center for the Prevention and Control of Important Animal Infectious Diseases and Zoonoses, Yangzhou University College of Veterinary Medicine, Yangzhou 225009, Jiangsu, People's Republic of China. 
Received: 30 June 2019 Accepted: 3 February 2020

Published online: 13 February 2020

\section{References}

1. Tkach W, Achatz TJ, Hildebrand J, Greiman SE. Convoluted history and confusing morphology: molecular phylogenetic analysis of dicrocoeliids reveals true systematic position of the Anenterotrematidae Yamaguti, 1958 (Platyhelminthes, Digenea). Parasitol Int. 2018;4:501-8.

2. Hildebrand J, Tkach WV. Description and phylogenetic relationships of Pojmanskatrema balcanica n. gen., n sp. (Digenea: Dicrocoeliidae) from the Eurasian water shrew Neomys fodiens (Mammalia: Soricidae) in Bulgaria. Acta Parasitol. 2019;64:282-7.

3. Pojmańska T. Family dicrocoeliidae looss, 1899. In: Bray RA, Gibson DI, Jones A, editors. Keys to the Trematoda, vol. 3. Wallingford: CABI Publishing; 2008.

4. Otranto D, Traversa D. Dicrocoeliosis of ruminants: a little known fluke disease. Trends Parasitol. 2003;1:12-5.

5. Kumar V. Trematode infections and diseases of man and animals. Dordrecht: Springer; 2013.

6. Basu AK, Charles RA. A review of the cat liver fluke Platynosomum fastosum Kossack, 1910 (Trematoda: Dicrocoeliidae). Vet Parasitol. 2014:200:1-7.

7. Pinto HA, Pulido-Murillo EA, Braga RR, Mati VLT, Melo AL, Tkach W. DNA sequences confirm low specificity to definitive host and wide distribution of the cat pathogen Platynosomum illiciens ( $=$ P. fastosum) (Trematoda: Dicrocoeliidae). Parasitol Res. 2018:6:1975-8.

8. Sitko J. Variability and systematic status of Zonorchis clathratum (Trematoda: Dicrocoeliidae), a parasite of swifts and swallows. Folia Parasitol. 1995:3:193-8.

9. Sitko J. Redescription of Skrjabinus skrjabini and validity reassessment of selected species of Skrjabinus (Digenea, Dicrocoeliidae). Helminthologia. 2013:4:281-6

10. Hildebrand J, Pyrka E, Sitko J, Jeżewski W, Zaleśny G, Tkach W, et al. Molecular phylogeny provides new insights on the taxonomy and composition of Lyperosomum Looss, 1899 (Digenea, Dicrocoeliidae) and related genera. Int J Parasitol Parasites Wildl. 2019;9:90-9.

11. Tkach VV, Pawlowski J, Mariaux J, Swiderski Z. Molecular phylogeny of the suborder Plagiorchiata and its position in the system of Digenea. In: Littlewood DTJ, Bray RA, editors. Interrelationships of the Platyhelminthes. London: Taylor \& Francis; 2001.

12. Olson PD, Cribb TH, Tkach W, Bray RA, Littlewood DTJ. Phylogeny and classification of the Digenea (Platyhelminthes: Trematoda). Int J Parasitol. 2003;7:733-55.

13. Hildebrand J, Pulis EE, Tkach WV. Redescription and phylogenetic relationships of the rare Lyperosomum sarothrurae Baer, 1959 (Digenea: Dicrocoeliidae). Acta Parasitol. 2015;3:371-7.

14. Hildebrand J, Sitko J, Zalesny G, Jezewski W, Laskowski Z. Molecular characteristics of representatives of the genus Brachylecithum Shtrom 1940 (Digenea, Dicrocoeliidae) with comments on life cycle and host specificity. Parasitol Res. 2016:4:1417-25

15. Aldhoun J, Elmahy R, Littlewood DTJ. Phylogenetic relationships within Dicrocoeliidae (Platyhelminthes: Digenea) from birds from the Czech Republic using partial 28S rDNA sequences. Parasitol Res. 2018;11:3619-24.

16. de Pérez-Ponce León G, Hernández-Mena DI. Testing the higher-level phylogenetic classification of Digenea (Platyhelminthes, Trematoda) based on nuclear rDNA sequences before entering the age of the nextgeneration' Tree of Life. J Helminthol. 2019;93:260-76.

17. Littlewood DTJ, Bray RA, Waeschenbach A. Phylogenetic patterns of diversity in the cestodes and trematodes. In: Morand S, Krasnov BR, Littlewood DTJ, editors. Parasite diversity and diversification: evolutionary ecology meets phylogenetics. Cambridge: Cambridge University Press; 2015. p. 304-19.

18. Locke SA, Van Dam A, Caffara M, Pinto HA, Lopez-Hernandez D, Blanar CA. Validity of the Diplostomoidea and Diplostomida (Digenea Platyhelminthes) upheld in phylogenomic analysis. Int J Parasitol. 2018;13:1043-59.

19. Liu GH, Yan HB, Otranto D, Wang XY, Zhao GH, Jia WZ, et al. Dicrocoelium chinensis and Dicrocoelium dendriticum (Trematoda: Digenea) are distinct lancet fluke species based on mitochondrial and nuclear ribosomal DNA sequences. Mol Phylogenet Evol. 2014;79:325-31.

20. Chang QC, Liu GH, Gao JF, Zheng X, Zhang Y, Duan H, et al. Sequencing and characterization of the complete mitochondrial genome from the pancreatic fluke Eurytrema pancreaticum (Trematoda: Dicrocoeliidae). Gene. 2016;1:160-5.

21. Lutz HL, Tkach W, Weckstein JD. Methods for specimen-based studies of avian symbionts. In: Webster MS, editor. The extended specimen: emerging frontiers in collections-based ornithological research studies in Avian Biology. Boca Raton: CRC Press; 2017.

22. Mettrick DF. Helminth parasites of Hertfordshire birds I. Trematoda. J. Helminthol. 1958;32:49-64.

23. Yamaguti S. Synopsis of Digenetic Trematodes of Vertebrates, vol. 1 and 2 Tokyo: Keigaku Publishing Co; 1971

24. Gasser RB, Hu M, Chilton NB, Campbell BE, Jex AJ, Otranto D, et al. Singlestrand conformation polymorphism (SSCP) for the analysis of genetic variation. Nat Protoc. 2006;1:3121-8

25. Tkach W, Littlewood DTJ, Olson PD, Kinsella JM, Swiderski Z. Molecular phylogenetic analysis of the Microphalloidea Ward, 1901 (Trematoda: Digenea). Syst Parasitol. 2003:1:1-15.

26. Burland TG. DNASTAR's Lasergene sequence analysis software. Methods Mol Biol. 2000;132:71-91.

27. Thompson JD, Gibson TJ, Plewniak F, Jeanmougin F, Higgins DG. The CLUSTAL_X windows interface: flexible strategies for multiple sequence alignment aided by quality analysis tools. Nucleic Acids Res. 1997;24:4876-82.

28. Kumar S, Stecher G, Tamura K. MEGA7: Molecular Evolutionary Genetics Analysis version 7.0 for bigger datasets. Mol Biol Evol. 2016;7:1870-4.

29. Ronquist F, Teslenko M, van der Mark P, Ayres DL, Darling A, Hohna S, et al. MrBayes 32: efficient Bayesian phylogenetic inference and model choice across a large model space. Syst Biol. 2012;3:539-42.

30. Darriba D, Taboada GL, Doallo R, Posada D. jModelTest 2: more models, new heuristics and parallel computing. Nat Methods. 2012:8:772.

31. Rambaut A: FigTree v1.4.4. 2016. https://github.com/rambaut/figtree/ releases. Accessed 01 Mar 2019.

32. Katoh K, Standley DM. MAFFT multiple sequence alignment software version 7: improvements in performance and usability. Mol Biol Evol. 2013:4:772-80

33. Laslett $D$, Canback B. ARWEN: a program to detect tRNA genes in metazoan mitochondrial nucleotide sequences. Bioinformatics. 2008:2:172-5.

34. Bernt M, Donath A, Juhling F, Externbrink F, Florentz C, Fritzsch G, et al. MITOS: improved de novo metazoan mitochondrial genome annotation. Mol Phylogenet Evol. 2013;2:313-9.

35. Zhang D, Gao F, Jakovlić I, Zou H, Zhang J, Li WX, et al. PhyloSuite: an integrated and scalable desktop platform for streamlined molecular sequence data management and evolutionary phylogenetics studies. Mol Ecol Resour. 2019. https://doi.org/10.1111/1755-0998.13096.

36. Wickham H. ggplot2: Elegant graphics for data analysis. 2nd ed. New York: Springer; 2016.

37. Librado P, Rozas J. DnaSP v5: a software for comprehensive analysis of DNA polymorphism data. Bioinformatics. 2009:11:1451-2.

38. Benson G. Tandem repeats finder: a program to analyze DNA sequences. Nucleic Acids Res. 1999:2:573-80.

39. Kolpakov R, Bana G, Kucherov G. mreps: efficient and flexible detection of tandem repeats in DNA. Nucleic Acids Res. 2003:13:3672-8.

40. Zuker M. Mfold web server for nucleic acid folding and hybridization prediction. Nucleic Acids Res. 2003;13:3406-15.

41. Talavera G, Castresana J. Improvement of phylogenies after removing divergent and ambiguously aligned blocks from protein sequence alignments. Syst Biol. 2007:4:564-77.

42. Kalyaanamoorthy S, Minh BQ, Wong TKF, von Haeseler A, Jermiin LS. ModelFinder: fast model selection for accurate phylogenetic estimates. Nat Methods. 2017;6:587-9.

43. Nguyen LT, Schmidt HA, von Haeseler A, Minh BQ. IQ-TREE: a fast and effective stochastic algorithm for estimating maximum-likelihood phylogenies. Mol Biol Evol. 2015;1:268-74.

44. Minh $B Q$, Nguyen MA, von Haeseler A. Ultrafast approximation for phylogenetic bootstrap. Mol Biol Evol. 2013;5:1188-95.

45. Letunic I, Bork P. Interactive tree of life (iTOL) v3: an online tool for the display and annotation of phylogenetic and other trees. Nucleic Acids Res. 2016:1·242-5. 
46. Littlewood DT, Lockyer AE, Webster BL, Johnston DA, Le TH. The complete mitochondrial genomes of Schistosoma haematobium and Schistosoma spindale and the evolutionary history of mitochondrial genome changes among parasitic flatworms. Mol Phylogenet Evol. 2006;39:452-67.

47. Robertson HE, Lapraz F, Egger B, Telford MJ, Schiffer PH. The mitochondrial genomes of the acoelomorph worms Paratomella rubra, Isodiametra pulchra and Archaphanostoma y/vae. Sci Rep. 2017;1:1847.

48. Kinkar L, Korhonen PK, Cai H, Gauci CG, Lightowlers MW, Saarma U, et al. Long-read sequencing reveals a $4.4 \mathrm{~kb}$ tandem repeat region in the mitogenome of Echinococcus granulosus (sensu stricto) genotype G1. Parasit Vectors. 2019;12:238.

49. Oey H, Zakrzewski M, Narain K, Devi KR, Agatsuma T, Nawaratna S, et al. Whole-genome sequence of the oriental lung fluke Paragonimus westermani. GigaScience. 2019;8:1-8.

50. Zhang D, Zou H, Wu SG, Li M, Jakovlić I, Zhang J, et al. Three new Diplozoidae mitogenomes expose unusual compositional biases within the Monogenea class: implications for phylogenetic studies. BMC Evol Biol. 2018;1:133.

51. Liu GH, Gasser RB, Young ND, Song HQ, Ai L, Zhu XQ. Complete mitochondrial genomes of the 'intermediate form' of Fasciola and Fasciola gigantica, and their comparison with F. hepatica. Parasit Vectors. 2014;7:150.
52. Yang X, Gasser RB, Koehler AV, Wang L, Zhu K, Chen L, et al. Mitochondrial genome of Hypoderaeum conoideum - comparison with selected trematodes. Parasit Vectors. 2015;8:97

53. Li WX, Zhang D, Boyce K, Xi BW, Zou H, Wu SG, et al. The complete mitochondrial DNA of three monozoic tapeworms in the Caryophyllidea: a mitogenomic perspective on the phylogeny of eucestodes. Parasit Vectors. 2017;1:314.

54. Zhang D, Li WX, Zou H, Wu SG, Li M, Jakovlic I, et al. Mitochondrial genomes of two diplectanids (Platyhelminthes: Monogenea) expose paraphyly of the order Dactylogyridea and extensive tRNA gene rearrangements. Parasit Vectors. 2018;11:601.

55. Briscoe AG, Bray RA, Brabec J, Littlewood DTJ. The mitochondrial genome and ribosomal operon of Brachycladium goliath (Digenea: Brachycladiidae) recovered from a stranded minke whale. Parasitol Int. 2016;65:271-5

56. Sokolov SG, Shchenkov SV. Phylogenetic position of the family Orientocreadiidae within the superfamily Plagiorchioidea (Trematoda) based on partial 28S rDNA sequence. Parasitol Res. 2017;10:2831-44.

\section{Publisher's Note}

Springer Nature remains neutral with regard to jurisdictional claims in published maps and institutional affiliations.
Ready to submit your research? Choose BMC and benefit from:

- fast, convenient online submission

- thorough peer review by experienced researchers in your field

- rapid publication on acceptance

- support for research data, including large and complex data types

- gold Open Access which fosters wider collaboration and increased citations

- maximum visibility for your research: over $100 \mathrm{M}$ website views per year

At BMC, research is always in progress.

Learn more biomedcentral.com/submissions 